\title{
A vision and compass for health care leadership: Lessons from the migrant nurse resolution for recurrent nursing shortages
}

This article was published in the following Dove Press journal:

Journal of Healthcare Leadership

17 August 2010

Number of times this article has been viewed

\section{Deleise SWilson \\ Richard W Redman \\ Kathleen M Potempa}

School of Nursing, University of Michigan, Ann Arbor, MI, USA
Correspondence: Deleise SWilson 400 North Ingalls, Ann Arbor, 48109-5482 MI, USA

$\mathrm{Tel}+|909-810-75| \mid$

Fax + I734-764-7I86

Email wilsonsh@umich.edu

\begin{abstract}
The ways migrant health care workers have been used internationally over the past decades demonstrates, in part, the global factors and effects of institutional leadership decisions. This example is especially illustrative in nursing given decades of the recruitment and exportation of nurses. The lessons for leadership in nursing may inform leaders in other health professions.
\end{abstract}

Keywords: health care leadership, leadership decisions

\section{Introduction}

The views on desired leadership behavior in recent times have changed by emphasizing principled decision-making and leadership ethics. Local, national and global events in the major sectors of society, such as the economy, politics, and health, not only influence governments but also impact decisions and strategies of leaders in organizations. ${ }^{1,2}$ Even leaders in organizations that do not operate in specific national or global markets are indirectly affected by, and impact the world environment. ${ }^{3}$ This increasing interconnectedness has broadened the responsibilities of leaders and the decisions they make in organizations as they face the many challenges of globalization. ${ }^{4}$ Economic uncertainty, persistent inadequate care for the poor, and the maturing of diversified populations worldwide pose particular challenges for leaders in health care. ${ }^{5}$

The historic difficulties related to the nursing workforce shortages are particularly illustrative of the complexity and interrelatedness of both local and global changes. ${ }^{6}$ For example, the migration of nurses from Africa continued during the unfolding of the devastating effects of HIV/AIDS when even more were needed. ${ }^{7}$ In the United States (US), the immigration of foreign nurses was overlaid on emerging health disparities among Americans. ${ }^{8}$ The role of nurses in low resource countries as compared to the US was not fully appreciated in this immigration which was largely initiated by US hospitals. ${ }^{9}$ In low resource countries nurses have pivotal roles not only in their specialty areas but are also community leaders, family advocates and government agents, while in high resource nations, the importance of the role of nurses was mainly contextualized within health care organizations. The loss of nurses to their communities in the country of emigration was enormous. The unilateral decision of hospital and nurse administrators to seek foreign nurses may not have been examined fully for the multifaceted effects within the national and international contexts.

This paper will use the example of nurse migration to demonstrate the need for leaders to have global understanding and perspectives as they make institutional decisions. 
In the case of the nursing workforce, the need to understand cultural and economic influences, the patterns of cross country migrations of nurses, the ethics of out-of-country recruitment, and the implication for leaders and the decisions they make, will be explored. The challenges of how to prepare and develop health care leaders of the future will also be discussed.

\section{Nursing workforce}

The migration of workers in health care tends to occur faster than in other industries..$^{10}$ The recruitment of foreign nurses by developed countries initially served the purpose of meeting perceived short-term demands during the 1960s to the early 1990s. ${ }^{11}$ By 2006, 8\% of the Canadian nursing workforce was comprised of foreign graduates. The majority of the nurses were recruited from the Philippines, but other source countries included Poland, China, and Romania. ${ }^{12}$ In the US 25\% of practicing doctors, $10 \%$ of nurses and $15 \%$ of other health care workers were trained abroad. ${ }^{13,14}$

The projected need for registered nurses in the US by 2025 exceeds $200,000 .{ }^{15}$ Notwithstanding an increase in the numbers of domestically trained nurses, the need to import foreign nurses persists. This recruitment strategy is driven by greater domestic demands, acceptance of foreign nurses beyond portal states by employers and patients alike, and the recognition of the nurse export business as a major form of international trade. ${ }^{16}$ This is especially pronounced in nursing homes and specialty care areas. The push for nurses away from their countries is usually caused by low wages, poor working conditions, and limited opportunities for professional development. Migrants can be voluntarily sent by their countries like the Philippines or involuntarily lost to their country such as in sub-Saharan Africa. ${ }^{17}$ The recruiting countries offer comparatively higher salaries, better working conditions, many opportunities for career advancement and improved standard of living for family members who remain at home. ${ }^{18}$

The practice of recruiting foreign nurses was supported by the 1965 Immigration Act aimed at meeting the need for skilled laborers in the U.S. and extended by the 1989 Nurse Relief Act. ${ }^{17(\mathrm{p} 39)}$ In conjunction with the National Council of State Board of Nursing (NCSBN), the Commission on Graduates of Foreign Nursing Schools (CGFNS) was established in 1977 to guarantee that the nurses entering the US workforce were competent in nursing content and English. ${ }^{6(\mathrm{p} 21)}$ Concomitantly, a major nurse exporting country, the Philippines, established the Philippines Overseas Employment Administration (POEA) in 1982 to facilitate the immigration process of thousands of Filipino nurses. ${ }^{17(\mathrm{p} 39)}$ Similarly, regional trade agreements by the Caribbean Community and Common Market (CARICOM) and the North American Free Trade Agreement (NAFTA) have expanded nurse migration among member countries. ${ }^{19}$ Bilateral trade agreements, and historical colonial ties have been major conduits for nurse recruitment from low resource Englishspeaking countries to the United Kingdom. ${ }^{20}$

\section{Globalization and health care}

The global expansion of the free market systems extends further into the realm of health care as evidenced by the phenomenon of health care tourism. ${ }^{21}$ The creation of high quality care for medical tourists and their families' fuels reverse migration patterns. Patients leave high resource countries for procedures in spa-like medical facilities, instead of skilled medical professionals departing for better economic opportunities in first world countries. ${ }^{22}$

Through the avenue of US hospitals and insurance companies collaborating with foreign countries, the partnerships have led to increased participation of developing countries in the policies of international health programs. ${ }^{10(\mathrm{p} 161)}$ For example, the Cleveland Clinic, Miami Hospital Miller School of Medicine, and Harvard Medical School have affiliations in countries in Central America, the Middle East and the Caribbean. ${ }^{23}$ Through the auspices of the World Health Organization and the Joint Commission International, over 220 private and public health care organizations in 33 countries are involved in setting international benchmarks for hospital risk reduction and best practices. ${ }^{24}$ As health care standards become universal the management of health care organizations will also become highly interdependent among countries.

While medical tourism opens the borders for cheaper medical care for visiting foreigners, there continues to be a gap in the quality of health care for locals in the participating countries. ${ }^{25}$ Ironically, global resource constraints for the funding and promotion of primary health care projects persist even in the presence of increasing medical revenues from medical tourism. The opening of borders for exchange of medical services has led to the examination of current trade policies regarding health care, which brings to the forefront discussions about the lack of effective policies for the management of health workers' resources. ${ }^{26}$ Movement of health care technology, supplies, consumers, workers, and the establishment of hospitals and treatment clinics have been largely sponsored by nongovernmental agencies and the private sector. ${ }^{10(\mathrm{p} 160)}$ The development of new policies requires vigorous debates with governmental agencies, health care 
entities, and international regulatory bodies. ${ }^{27}$ For example, using the platform of the World Trade Organization's Agreement on Trade-related Aspects of Intellectual Property Rights (TRIPS), the Ministries of Health in Malaysia and Thailand were able to capitalize on provisions within the agreement to lower the cost of importing patented drugs. ${ }^{10(\mathrm{p} 160)}$ Similar negotiations under the General Agreement on Trades in Services can address global maldistribution of health care workers. $^{28}$

\section{Globalization of the health care worker crisis}

The crisis of the migrant health care workers is more evident in nursing given the long history of nurse recruitment and exportation. Nurses account for the largest group of immigrant health workers. The shift of health care workers from donor countries to high resource countries highlights several ethical implications. The loss of professionals from the low resource countries contributes to an uncompensated brain drain. Not only is the brain drain immediately felt in the provision of health services to the local population, but it also has ramifications for the future of the profession. With large segments of the educated population leaving for more developed countries, the quality of education for upcoming generations is compromised. The source countries do not generally receive reparations for educating professionals. ${ }^{29}$ Breaches in the professional infrastructure of the source country tend to occur that lead to deficits in the supply of future professionals. ${ }^{30}$

Also, acute shortages of health care workers are now being reported by low resource countries. In many of the countries with low health care worker resources, the "health worker density", ratio of health care workers to population, was less than 2.5 workers per 1,000 individuals within the population for 75 countries. ${ }^{31}$ Many of these low density countries are exporters of health care workers. Correspondingly, in the donor countries there is depletion of health services to the poor. ${ }^{32}$ In regions of the world like sub-Saharan Africa where there is a geographical concentration of donor contiguous countries, large geographical areas of sub-standard health services contribute to the difficulty of reducing the high rates of HIV/AIDS, malaria, maternal deaths from complications of pregnancy and low vaccination rates. ${ }^{33,34}$

In addressing the migrant health care worker crisis, the Joint Learning Initiative (JLI) identified the increased demand placed on developing countries in the wake of HIV/AIDS, persistent labor migration to richer countries, and an extended lack of emphasis on human resource development during health care reform as contributing factors. ${ }^{31(\mathrm{p} 1)}$ The potential for the global health care worker deficit is projected to worsen. To promote global equitable health care and combat the negative consequences on developing countries, the JLI emphasized the development of effective governmental policies to manage local, national and transnational migration of health workers. Although these recommendations for the improvement of globalized health care are timely and may be very effective for the management of the crisis, health care leaders need the tools to forestall the next latent crisis.

The factors that pushed the nurses from the urban areas in the US are strikingly similar to the health care crises now evident in low resource countries by the migration of health care workers. The mismatch in this dynamic is the powerful pull of the promise of better financial, educational, and professional opportunities in the high resource countries, which are too persuasive for the individual professional and formidable for governments. While the local context was obvious from the beginning, and the possible solutions overlooked the long term implications on developing countries, health and health care, economies and workforce planning were largely ignored.

Using the nursing shortage crisis as a case study, one of the important lessons learned is that the recruitment of foreign nurses met a short-term local need that was by all accounts a latent symptom of pending larger global problems. Would the magnitude of the current lack of nurses now seen in high resource countries and globally have been reduced if there was another approach to solving the nursing shortage? What may have been the result of investments in the development of local sources of supply for nurses like increased training of under represented minority students from urban areas? Were the leaders making these initial decisions fully aware of the short and long term consequences beyond their own institutions? What implications can be gleaned from past decisions about the recruitment of foreign nurses in terms of what is required of leaders today who function within a global context?

\section{Changing views on health care leadership}

A consideration of the historical contexts that initiated the need for foreign nurses in the US may serve as an example of leadership decisions that were hailed as successful in the immediate and local context. Brush's examination of the politics of place and race argues that the rapid development of American urban neighborhoods and subsequent health care systems in the 1960s and 1970s were superimposed on the 
racial conflicts that influenced political and organizational decision making. ${ }^{35}$ As the urban hospital systems developed and were mainly serving minority or indigent populations, nurse staffing vacuums were created as nurse leaders were unable to recruit and retain white nurses. Brush suggested that the predominant practice of limiting the entry of blacks into nursing programs resulted in missed opportunities to train and educate minority nurses who may have filled the vacancies in the urban areas created in part by the flight of white nurses. The prevailing mindset of nurse leaders responding to the acute nursing shortages in the 1960s reflects the effect of leadership in shaping destiny. According to the 2008 National Sample Survey of Registered Nurses (NSSRN), the non-white registered nurses still remains less than twenty percent of the American nursing workforce. ${ }^{36}$

The lessons learned about nurse leaders' experiences of struggling with cyclical shortages of nurses can provide good insight into the changing views of health care leadership today. In the past, nurse leaders were operating with an orientation toward short term gain and in ways that were beneficial to their own institutions. The impact of decisions around recruitment of foreign educated nurses was beneficial to the leaders' institutions without a clear understanding or consideration of how those recruitment or migration decisions were affecting the global market, especially in underserved areas.

Formerly, leaders were associated functionally with positions and power and their effectiveness was analyzed in terms of roles and responsibilities with an eye to goal accomplishment. Past leadership theories, in general, have not incorporated elements of ethics in their frameworks. Interest in ethical principles and how they might be reflected in leadership behavior and decision-making has been greater than before, given the examples of leadership scandals in both the corporate and political worlds. Current views on leadership now stress principles of ethical leadership to include elements such as respect, service, justice, honesty, and community. Thus, ethical leaders serve others, make decisions that serve the common good and community goals. ${ }^{37}$ Examples of this ethical lens for leader behavior are increasingly evident. ${ }^{38-40}$

The practice of training leaders within programs of their own professions may be counter intuitive to what is actually needed in real world practice. Since the late 1970s there has been a rise of the doctor of practice programs for pharmacists, physical therapists, and nurses. ${ }^{41}$ Additionally, medical doctors are seeking joint degree programs such as MD/MBA and MD/MPH. The emphasis of these programs is on management within the clinical setting, but many have objectives aimed at providing the graduates with the tools necessary to deal with uncertainty and working with a multidisciplinary team. Crites, Ebert and Schuster, noted that the overall emphasis of the dual MBA/MPH programs is on business or public health management and less on leadership. ${ }^{42}$ They stated that many of the dual degree programs did not have an explicit focus on leadership development, but the aim is to equip health care leaders to be knowledgeable of many aspects of health care management.

Similarly, the preparation of leadership for singular professional and organizational settings or for restricted geographical locations limits the ability to grapple with problems and issues that defy those boundaries. Heathcare leaders develop innovative leadership by participating in non-hospital settings which require novel ways of confronting challenges. In discussing a lifetime of successful nurse leadership, McDonagh described how venturing out to work with community health worker programs, mobile health services, philanthropic organizations, and new health care technologies increased her collection of skills that enhanced her resourcefulness as a leader. ${ }^{43}$

\section{Creating visionary health care leaders}

The preparation of visionary leaders who will make the types of decisions needed in today's complex environment requires innovative approaches to education. The rapid and far reaching consequences of change make reliance on textbooks, that may become irrelevant soon after print, an obsolete methodology. Aspirant leaders will benefit from classes that involve live discussion with leaders in industries that are providing innovative service and products in response to current market demands instead of a ten week seminar.

In a recent study surveying the perception of medical education by medical students, less than $40 \%$ reported having appropriate training in the practice of medicine, which includes knowledge of the health care system. ${ }^{44}$ Many leadership roles include daily interaction with the leaders from multi-disciplinary teams. Exposure to interdisciplinary education enhances the potential for collaboration in the work environment. ${ }^{45}$ This is a component missing in many curricula in health professions education programs today.

Current health care leaders wrestle with planning for the next wave of needs by studying the current situations and projecting the solutions without having the benefit of past successes to guide the development process. The leadership student may partake in the process of creating 
solutions instead of merely applying answers that may no longer be relevant. This type of leader functions at the cutting edge of issues and not in the daily management of organizations. The provision of opportunities for future leaders to interact at the academy with students from other disciplines may develop the working relationships that are likely to be the focus of the practice environment.

Specific competencies have been identified as essential components of nurse leaders' repertoire. This skill set includes: a global perspective regarding health care and professional nursing issues; the ability to create organizational cultures that permeate quality and patient safety; highly developed collaborative and team building skills; the ability to balance authenticity and performance expectations; and the ability to adapt to an environment characterized by chaos and rapid change. ${ }^{46}$

Contemporary views of leaders place much greater emphasis on the values, charisma, and vision of the individual leader and how those qualities are used to inspire, even transform, individuals, work groups and societies. The principles, values and ethics of the leader are seen as central to the influence and the impact of the leader. Leaders are described in terms of their integrity and authenticity. The emphasis is on the responsibility that leaders have in influencing and inspiring people, transforming society, and creating a preferred future. ${ }^{47}$

In a meta-analysis of 201 research studies examining interventions aimed at preparing more effective leaders, the results revealed that the probability of a positive impact from leadership development programs is at least 63 percent across all studies. This impact holds regardless of the setting, theory, or measure used. ${ }^{48}$ While it does not provide certain evidence, it does indicate that interventions are available to help individuals learn and develop desired leadership qualities at a reasonable level of success. This is the challenge that we face as we educate health professions, students for their future roles and responsibilities.

\section{Conclusions}

Globalization of the world and its implications were not even foreseen by national leaders in the enacting of the United States 1952 Immigration Act. The flattening of the world exposes the finite nature of resources and the interconnectivity of the strategies that can link an organization in large urban cities to remote mountain villages via global migration. Therefore, health care leaders who activate strategic plans to address local problems may benefit from projecting the impact on ever widening circles of possible social, political, cultural and ethical outcomes. Innovative leaders will operate with a heightened awareness of the new global context in which health care is delivered and managed. Health care issues and crises may be best addressed by multi-disciplinary team members who bring to the table social, economic, political, ethical and cultural understanding from the local, national and international perspectives that will bear upon the host organization. An understanding of the issues and needs of broad based constituency will assist decision makers in providing solutions that support communities as well as institutions.

Principled leaders are needed who have a collaborative vision beyond disciplinary or national borders and are able to deal with issues and challenges from the perspective of the common good. This is evident in the Code of Practice on International Recruitment of Health Personnel approved recently by $\mathrm{WHO} .{ }^{49}$ Innovative leadership suggests that there should be scrutiny of presenting issues to consider contexts, characteristics and consequences which may be lost in the rush for quick solutions. Visionary leadership, in addition to organizational and managerial perspectives, is necessary if solutions are to have long term benefits.

Training of future generations of leaders will need to emphasize global perspective over local, ethical integrity over self-serving strategy, and societal benefit over institutional or disciplinary gain. Identifying methods and strategies to accomplish this must be a top priority for all health disciplines.

\section{Disclosure}

The authors report no conflicts interest in this work.

\section{References}

1. Zakaria F. The Post-American World. New York, NY: W.W. Norton and Company; 2008.

2. Richards J. We are all in this together. Nurs Leadersh. 2010;22(4): $18-19$.

3. Friedman TL. Outsourcing, schmoutsourcing! Out is over. NY Times. com; [Cited 2006, May 19]. Available from: http://select.nytimes. com/2006/05/19/opinion/19friedman.html. Accessed Mar 3, 2010.

4. Brooks JS, Normore AH. Educational leadership and globalization: Literacy for a global perspective. Educ Pol. 2010;24(1):52-82.

5. Fried BJ, Harris DM. Managing healthcare services in the global marketplace. Front Health Serv Manage. 2007;24(2):3-18.

6. Brush BL. Global nurse migration today. J Nurs Scholarsh. 2008; 40(1): $20-25$.

7. Dovlo D. Migration of nurses from Sub-Saharan Africa: A review of issues and challenges. Health Serv Res. 2007;42(3 Pt II):1373-1388.

8. Williams DR, Collins C. US socioeconomic and racial-differences in health-patterns and explanations. Annu Rev Sociol. 1995;(21): 349-386.

9. Salmon ME, Yan J, Hewitt H, Gusinger V. Managed migration: The Caribbean approach to addressing nursing services capacity. Health Serv Res. 2007;42(3):1354-1372.

10. Chanda R. Trade in health services. Bull World Health Organ. 2002;80(2):158-163.

11. Brush BL, Sochalski J, Berger AM. Imported care: Recruiting foreign nurses to US health care facilities. Health Aff. 2004;23(3):w78-w87. 
12. Blythe J, Baumann A. Internationally educated nurses: Profiling workforce diversity. Int Nurs Rev. 2009;56(2):191-197.

13. Weiner JP. Expanding the US medical workforce: Global perspectives and parallels. BMJ. 2007;(335):236-238.

14. Hooper CR. Adding insult to injury: The healthcare brain drain. J Med Ethics. 2008;34(9):684-687.

15. Buerhaus PI, Auerbach DI, Staiger DO. The recent surge in nurse employment: Causes and implications. Health Aff. 2009;28(4): w657-w668.

16. Polsky D, Ross SJ, Brush BL, Sochlaski J. Trends in characteristics and country of origin among foreign-trained nurses in the United States 1990-2000. Am J Public Health. 2007;97(5):895-899.

17. Brush BL, Sochalski J. International nurse migration: Lessons from the Philippines. Policy Polit Nurs Pract. 2007;8(1):37-46.

18. Zarocostas J. Poor countries urgently need to scale up training of healthcare workers, task force warns. BMJ. 2008;336(7655):1211.

19. Kingma M. Nurses on the move: A global overview. Health Research and Educational Trust. 2007;42(3 Pt II):1281-1298.

20. Buchan J. International recruitment of nurses: Policy and practice in the United Kingdom. HSR. 2007;42(3 Pt II):1321-1335.

21. Merrell RC, Boucher D, Carabello L, et al. Roundtable discussion medical tourism. Telemed J E Health. 2008;14(1). Retrieved from: http://www.liebertonline.com/doi/pdfplus/10.1089/tmj.2008.9995. Accessed Jan 20, 2010.

22. York D. Medical tourism: The trend toward outsourcing medical procedures to foreign countries. J Contin Educ Health Prof. 2008;28(2):99-102.

23. Rotenberk L. As the world flattens, U.S. hospitals expand their reach. Hosp Health Netw. 2008;82(6):14.

24. Joint Commission Resources. International accreditation and certification. Retrieved from: http://www.jcrinc.com/About-JCI/ Accessed Jan 19, 2010.

25. Lautier M. Export of Health services from developing countries: The case of Tunisia. Soc Sci Med. 2008;(67):101-110.

26. Blouin C. Trade policy and health: From conflicting interests to policy coherence. Bull World Health Organ. 2007;85(3): 169-173.

27. Diallo K. Data on the migration of health-care workers: Sources, uses, and challenges. Bull World Health Organ. 2004;82(8):601-607.

28. Khaliq AA, Broyles RW, Mwachofi AK. Global nurse migration: Its impact on developing countries and prospects for the future. Nurs Leadersh. 2009;22(1):24-50.

29. Hamilton K, Yau J. The global tug of war for health care workers. Retrieved from: http://www.migrationinformation.org/feature/print. cfm?ID=271. Accessed Apr 20, 2010.

30. McElmurry BJ, Solheim K, Kishi R, Coffia MA, Woith W, Janepanish P. Ethical concerns in nurse migration. J Prof Nurs. 2006;22(4): 226-235.

31. Hanvoravongchai P. The Joint Learning Initiative report: Overcoming the crisis. Available from: http://www.eldis.org/go/home\&id= 46070\&type=Document. Accessed Feb 7, 2010.
32. Ahmad OB. Managing medical migration from poor countries. $B M J$. 2005;331(7507):43-45.

33. Scheffler RM, Mahoney CM, Fulton BD, Dal Poz MR, Preker AS. Estimates of healthcare professional shortages by 2015. Health Aff. 2009;28(5):w849-w862.

34. Dovlo D. Taking more than a fair share? The migration of health professionals from poor to rich countries. Retrieved from: PLoS Med. 2005;2:e109. doi: 10.1371/journal.pmed.0020109. Accessed Jan 19, 2010.

35. Brush BL. Has foreign nurse recruitment impeded African American access to nursing education and practice. Nurs Outlook. 1999;47: 175-180.

36. Department of Health and Human Services. The registered nurse population: Initial findings from the March 2008 National Survey Sample of Registered Nurses. Retrieved from: http://bhpr.hrsa. gov/healthworkforce/rnsurvey/initialfindings2008.pdf. Accessed Apr 20, 2010.

37. Collins J. Good to Great. New York, NY: HarperCollins Publishers Inc.; 2001.

38. Lencioni P. The Five Dysfunctions of a Team. San Francisco, CA: Jossey-Bass; 2002.

39. Deal TE, Bolman LG. Leading with Soul: An Uncommon Journey of Spirit. San Francisco, CA: Jossey-Bass; 2001.

40. Deal TE, Bolman LG. Reframing Organization: Artistry, Choice, and Leadership. 3rd ed. San Francisco, CA: Jossey-Bass; 2008.

41. Allen DD, Penn MA, Nora LM. Interdisciplinary healthcare education: Fact or fiction? Am J Pharm Educ. 2006;70(2): article 39.

42. Crites GE, Ebert JR, Schuster RJ. Beyond the dual degree: Development of a five-year program in leadership for medical undergraduates. Acad Med. 2008;83(1):52-58.

43. McDonagh KJ. Leadership in innovation: Life beyond the hospital. Nurs Adm Q. 2009;33(4):325-328.

44. Patel MS, Lypson ML, Davis MM. Medical student perceptions in health care systems. Acad Med. 2009;84(9):1301-1306.

45. Thai A, Draugalis JR. Dual PHARM/MBA programs 20012002: A descriptive report. Am J Pharm Educ. 2002;(6 winter): 372-377.

46. Huston C. Preparing nurse leaders for 2020. J Nurs Manag. 2008;16(8):905-911.

47. Northouse PG. Leadership: Theory and practice. 4th ed. London, UK: Sage Publications; 2007.

48. Avolio BJ, Luthans F. The high impact leader: Moments matter in accelerating authentic leadership development. New York, NY: McGraw-Hill; 2006.

49. World Health Organization. (2010). WHO Global Code of Practice on the International Recruitment of Health Personnel. Accessed on May 28, 2010 at: http://www.who.int/hrh/migration/en/index.html
Journal of Healthcare Leadership

\section{Publish your work in this journal}

The Journal of Healthcare Leadership is an international, peer-reviewed, open access journal focusing on leadership for the health profession. The journal is committed to the rapid publication of research focusing on but not limited to: Healthcare policy and law; Theoretical and practical aspects healthcare delivery; Interactions between healthcare and society and evidence-based practices;

\section{Dovepress}

Interdisciplinary decision-making; Philosophical and ethical issues; Hazard management; Research and opinion for health leadership; Leadership assessment. The manuscript management system is completely online and includes a very quick and fair peer-review system. Visit http://www.dovepress.com/ testimonials.php to read real quotes from published authors. 